\title{
Engineering Education in an Industrial Context
}

\author{
http://dx.doi.org/10.3991/ijac.v8i2.4680 \\ T. Hagenreiner ${ }^{1,2}$, G. Engelmann ${ }^{3}$ and P. Köhler ${ }^{2}$ \\ ${ }^{1}$ BMW AG, Munich, Germany \\ ${ }^{2}$ University of Duisburg-Essen, Duisburg \\ ${ }^{3}$ University of Dresden, Dresden
}

\begin{abstract}
Learning is a lifelong process, which may not end at the transition from school to work. To exploit modern software systems used in design engineering, in order to increase efficiency and stay competitive, engineers have to keep on gaining knowledge during occupation. Anyhow, employees are usually not or only insufficiently trained, as no working time shall be lost. This paper demonstrates an opportunity to implement a learning-by-doing within the development process by the utilization of a Knowledge Based Engineering System (KBES). The user is supposed to be able to improve efficiency and quality in design engineering without the need of time-consuming trainings. Instead he/she is getting a short introduction (10 to 15 minutes), which can take place anytime during work. Therefore, product- and process-knowledge is saved within a knowledge-base and provided to the user in a way allowing him/her to use the system intuitively as he/she is guided through the process. As each step of the system may be reconstructed in the structure tree of the CA-system, the user understands the basic concepts in an implicit way. An experimental study is conducted to prove the effects of the KBES. The results clearly show that the efficiency and dataquality can be raised by the usage of such a system. Furthermore the study proves that there is a learning effect as the test persons could improve their results on a more complicated task after about four to six weeks past the introduction. The results may be explained with the Cognitive-Loadtheory regarding the method of Worked-Out-Examples.
\end{abstract}

Index Terms-Cognitive Load Theory, implicit learning, KBE, Knowledge Based Engineering, Worked-Out Examples

\section{INTRODUCTION}

The increasing globalization in the automotive industry is putting a high competitive pressure on companies. In order to assert themselves within the global competition, automotive companies have to create efficient working processes and continue to develop and improve the latter. Nowadays, the basis for this are software systems which are also further developed in a fast manner. Those systems often attain a complexity, which can only be handled by experts. As such an expertise is very specific, it is usually not teached entirely within a degree program. Instead, copious foundations are created which are deepened according to a certain task during occupation. Therefore, young professionals always have to go through a learning process while they are already working productive. This is well known and accepted by the employer. The workload is accordingly smaller at the beginning. Employees working in a job for several years usually obtain no or only little time for learning activities, although it might be needed for different reasons, like the just mentioned fur- ther development of software systems. Furthermore, employees gain additional responsibilities, which afford the usage of new tools. Another point is the fact that there is a high fluctuation especially in big companies which is partly desired, as it is providing the opportunity to hire employees on a lower salary level [1]. Highly paid workers are moved to positions with more responsibility in return. Another reason is the engagement of external service providers to increase flexibility. The contract award is referred to the project, not a certain person. This way, there are more changes of working persons within a project for an optimal capacity utilization of the service providers' staff.

Especially the early phase in the field of product engineering is characterized a lot by virtual methods. Hedges may be performed earlier, costing only a fraction compared to experimental set-ups. Base for feasibility studies and simulations within diverse domains are threedimensional CAD-models. The learning of engineering design methods is an inherent part of a variety of engineering studies, whereas the depth of education ranges from basic functions of volume-modeling to techniques of automated product configuration [2]. Advanced methods of construction allow major efficiency enhancements with simultaneously increasing data-quality if the user is capable to exploit the full potential of the highly priced software. A study with 153 powertrain engineering designers from an automotive company and suppliers shows that this is very uncommon [3]. According to these investigations only $14 \%$ of participants are using the possibilities offered by the provided CA-system. $85 \%$ state that they are missing the methods to identify, classify and determine the necessary parameters and associative relationships. Young professionals do not have the experience needed. Experts with many years of experience have similar problems as well, as the construction process has changed a lot with the development of parametric systems. Therefore, engineering designers have to familiarize themselves with the parameterization-process in order to exploit the potential [4]. Furthermore there is a constant integration of new functionalities.

Concerning the superior goal of efficiency enhancement within the development process, extensive trainings would be sensible, as they lead to major time savings by creating CA-models. Furthermore, there are considerable advantages with variant constructions and subsequent processes, for which the data-quality is crucial. The bottleneck for structural analysis is for example the preprocessing (preparation of data for the calculation), which takes most of the time needed for structural analysis [5]. The redemption of the time for education would be accomplished accordingly fast. Nevertheless, employees in 
PAPER

ENGINEERING EDUCATION IN AN INDUSTRIAL CONTEXT

an industrial environment are hardly trained intensively, because they cannot work productively during this time.

The aim of this paper is to demonstrate an approach how young professionals as well as employees with several years of experience can be enabled to exploit the full potential of software-systems without attending training classes on the expense of working time, by means of modern methods of virtual product engineering. A knowledge based engineering system (KBES) is introduced, which, amongst others, is a technique for design automation [6, 7], allowing the user to increase the efficiency and dataquality by utilizing integrated knowledge without demanding specific know-how (of the construction method / respective component). Thereby, the time for incorporation of inexperienced workers is reduced [8]. Furthermore, an implicit learning effect is supposed to be established which corresponds an acquisition of knowledge mostly independent of conscious learning-attempts and without the existence of explicit knowledge about what is acquired [9]. Goal is to generate tacit knowledge through learning by doing. The term 'tacit knowledge' describes personal, context-specific knowledge, which is difficult to communicate, resulting from the experiences of the individual [10].

To reach these goals, the represented KBES contains expert knowledge of the structural setup of a component as well as about each single construction step necessary in form of construction packages. The programmatic summary and automated execution offers the possibility to realize construction procedures in a few minutes, which would take days in the conventional manner [11]. The user has the opportunity to access the packages successively over a graphical user interface (GUI) provided in the familiar working environment. The general goal to free the user of repetitive tasks by means of knowledge based methods to give him more time for creative processes [12] is pursued here, too. The focus is put on a structure allowing major changes by the manipulation of basic elements. This way, non-sophisticated users are enabled to realize their ideas in a fast and uncomplicated manner. To what extent the mentioned goals may be achieved is proofed by an experimental study.

The paper is structured as follows: section two describes the relevant theoretical foundations of learning methods together with previous works regarding the applied methods in the domain of product engineering. Section three discusses the specific challenges of the construction work by the example of automotive headlamps and an appropriate KBE-system, which serves as a case study for the following investigations. In the subsequent part boundary conditions of the experimental study are defined, the execution is described and the results are presented. Conclusions are drawn in the fifth section. The work is finished with a summary and an outlook.

\section{THEORETICAL CONTEXT}

\section{A. Worked-Out Examples}

Learning is a lifelong process, which bears over the occupational context. Thereby information is gathered, processed and implemented [13]. An efficient way of integrating learning and work is the method of 'worked-out examples'. It is characteristic for domains in which algorithmic knowledge has to be understood and applied [14]. It is therefore a problem with a worked-out solution that has to be comprehended by learners. It consists of a formulated problem, the solution steps and the final solution itself [15]. After the explanation of a principle, it is demonstrated how it may be applied. Afterwards, the learners have to solve an exercise on their own. Effective learning effects appear especially when the phase of studying the solution example is intensified and enlarged [16]. A variety of studies show that worked-out examples are meaningful especially at the initial acquisition of cognitive skills in scientific domains like mathematics or physics [17]. According to Stark [18] and Renkl [17], learners prefer worked-out examples in relation to other learning medias and rightly so, as the learning with such examples is effective and efficient. The instructional configuration of the learning situation may be varied such that there is more space for the actual learning processes. This way the working memory is stressed to a lower extent so that learners are able to use their cognitive capacities for the deepening of their understanding [19].

Numerous experiments proofed that learners favor the usage of examples [20]. Concerning the solving of exercises by inductive conclusions it was investigated to what extent learners orient themselves towards previously described examples or teaching texts, which illustrate abstract principles. It was revealed that the majority of participants oriented themselves towards the examples. Worked-out examples have a significant role especially in the early phases of knowledge acquisition [21]. At the beginning learners are often dependent on examples which is reflected by the fact that they are often incapable to solve exercises which only differ to small extents from the provided examples [18].

The receipt of initial cognitive skills by means of learning with worked-out examples is particularly high when the learning persons are able to explain and reconstruct the logic of the examples by themselves [22]. The term of "self-explanation" in the context of learning through worked-out examples was introduced by Chi et al. [23]. In order to really understand the learning material, a student has to draw conclusions and make inferences. He/She needs to provide explanations (either overtly or covertly) for why a particular action is taken. "Only then will the student be able to apply the acquired procedure to nonisomorphic problems that do not match exactly the conditions of the example solution" [23]. According to Renkl [17] these conclusions are called principle-based explanations and are of great importance as learners are gaining a deeper understanding of the solution procedure. They know how to link the solution steps to the basic principles of a topic area. Finally cutting out the examples step by step supports an autonomous processing of exercises, especially concerning the automation of skills and their delicate adjustment.

\section{B. Cognitive Load Theory}

Sweller and Cooper [24] analyzed learning through worked-out examples as well as learning though problem solving in the context of knowledge acquisition in algebra. Thereby learning by means of worked-out examples resulted in benefits at the generation of cognitive patterns, which support the transfer of the learned content to new problem cases. The instructional superiority of worked-out example conditions over problem solving conditions could also be replicated in the domain of physics [25]. The effectiveness may be explained by the cognitive-load theory 
[26]. It sets up a relation between the initial performance of gaining cognitive skills and the capacity limitations of the human information processing system. The cognitiveload theory deals in particular with the restrictions of single modules of the working memory and the consecutive instructional consequences. Cognitive load occurs in succession of the amount of information, which have to be available for cognitive operations during the processing of certain tasks as well as the demanded processing methods [27]. Such a limitation becomes problematic as soon as there are more information units required than memory capacity is available. The information processing system is overtaxed and the possibility of failures increases considerably [16]. There are three types of cognitive load [27]:

- Intrinsic load is determined by the complexity of the learning material in relation to the previous knowledge of the learner.

- Extraneous load describes the information processing workload. It is determined by the instructional organization of the learning situation and can therefore be altered.

- Germane load describes the cognitive load resulting from the actual learning processes.

The goal of the instructional constitution of learning situations is to generate a high amount of germane load. According to cognitive-load theory, the advantage of learning with worked-out examples is, that the latter cause a small extraneous load giving more space to the actual learning processes (germane load). Learners are freed from problem solving activities, which demand a high extraneous load, blocking capacities for the actual learning process. The working memory is less stressed so that learners can use their cognitive capacities to deepen their understanding [19].

\section{Virtual Product Engineering}

High-performance CAD-systems represent the basic tool in product engineering nowadays. Approaches to generate intelligent CAD-systems by integrating a processing of knowledge were already investigated in the end of the 1980s [28]. Ever since the trend of implementing an information processing within this context has increased. Therefore CA-models are not only a virtual representation of geometry any more. They have become data-pools, too [29]. The German Association of Engineers (VDI - Verein deutscher Ingenieure) defines knowledge-based parametrics as a method to give the user the freedom to expand existing models by adding design rules, allowing an integrated acquisition and processing of knowledge [30]. This way the geometry is determined by knowledge in form of design and configuration rules instead of dimensional parameters. They may include not only geometric and non-geometric rules but also checking rules as may be seen in Tab. 1.

The subsequent development step is the feature technology. Per definition, a feature is the "aggregation of geometry items and/or semantics" [31]. The mapping of semantic information to interpret the information, which is available, states a crucial property of a feature. There are predefined features by the CA-system, like drillings for example, as well as the opportunity to create user-defined features. Basically everything that may be activated by a user dialog in order to build resp. complete the generation
TABLE I.

TYPES OF RULE IN KNOWLEDGE-BASED PARAMETRICS [30]

\begin{tabular}{|l|l|}
\hline Type & Example \\
\hline $\begin{array}{l}\text { Geometric rules } \\
\text { or parametrics }\end{array}$ & $\begin{array}{l}\text { Width is 20 mm. the height is half the width. } \\
\text { width=20, height = width/2 }\end{array}$ \\
\hline $\begin{array}{l}\text { Non-geometric } \\
\text { rules }\end{array}$ & $\begin{array}{l}\text { If the type designation of the adapter is KM40, a } \\
\text { diameter of a hole should be 5, otherwise 10. } \\
\text { diameter: if (adapter?: = "KM40" then 5 else 10 }\end{array}$ \\
\hline Checking rules & $\begin{array}{l}\text { If value1 is greater than value2, a warning mes- } \\
\text { sage with the text "Please check your input!" } \\
\text { should be output. } \\
\text { If (\$valuel > \$value2) then } \\
\text { print message ('“Please check your input!"';; }\end{array}$ \\
\hline
\end{tabular}

of a product model is linked to the 'feature'-term [32]. Further explanations and examples of feature-types may be found in [33].

"The technology of Knowledge Based Engineering (KBE) extends feature oriented and parametric-associative product modeling by rule-based modeling techniques, know-how, rules, analysis and checking functions (model checking), event-driven routines as well as custom specific optimization processes" [34]. It represents an evolutionary step in Computer Aided Engineering (CAE) by merging the CAD technologies with the domains of object oriented programming (OOP) and techniques of artificial intelligence (AI), giving benefit to automation solutions [35]. With the automation of design tasks by embedding engineering knowledge, leading industrial companies, exploiting $\mathrm{KBE}$, have shown dramatic return on investment [36]. A reason therefore is the possibility to create highly specific solutions meeting exactly the demands of the user. Therefore, not only the capabilities of the CAsystem may be used, but also any external CAE-tool providing an application programming interface (API). With this scope of possibilities, KBE enables not only saving information for a single design, but to model the whole process of how to generate the design [37]. This fact is especially important for the current work, as it enables, in combination with the possibility to create graphical user interfaces (GUI), a guiding of the user through the construction process.

As the development and maintenance of KBE applications is a complex undertaking, many scientific researches deal with the description of how to create such a system [38-40]. The KNOMAD - methodology is providing six basic steps for this issue [40]:

- $\quad$ Knowledge Capture: identification and capturing of relevant knowledge.

- Normalization: raw knowledge is subjected to quality control and normalization.

- Organization: providing a knowledge structure for various stakeholders.

- Modeling: Generation of product models and processes.

- Analysis: Calculation of design implications on single disciplines.

- Delivery: Performance of a design solution acceptance check.

\section{Creation Of The KBE-System}

To what extent the goals mentioned at the beginning may be achieved by a KBE-application shall be constituted by the case study of the engineering design work of automotive headlamps. Therefore the specific problems 
are outlined and the functionalities of the system are explained. Further information on the KBES serving as basis for the investigations may be found in [41-43].

The headlamp component (Fig. 1) is a well-suited example because of the variety of requirements from a technical point of view, statutory rules and the strong influence of the design on the appearance of the whole car. The high number of competing influencing factors is leading to complex shapes, which have to be adopted a lot within the development process. Besides there has to be the possibility to extrapolate different variants of a basic construction.

The first step in the development of a headlamp is always the modeling of the outer lens. Based on a design surface, describing the outer skin of the vehicle, a volume body has to be created. This is already a demanding challenge, as there is no geometry, which can be used as reference in this state. Therefore, at the beginning, a wireframe-structure must be build, which may only refer to the axis system and the input surface. On this basis, a surface- and finally a volume-model can be generated. To accomplish the demands on robustness and flexibility (factors for data-quality [7]) a strict parametric structure has to be pursued from the very beginning, which has been developed and improved over many years to meet the requirements. For this purpose a lot of ancillary elements are necessary resulting in a total of about 4000 construction elements for one outer lens. While the creation of a component is a highly creative process, the structural construction work to generate a parametric model is mainly an algorithmic workflow. To gather this workflow and save it in the knowledge-base, a series of expertinterviews was held. Furthermore, the knowledgeengineer (creator of the KBES) conducted the whole construction of the component by himself, to recognize the relevant information and filter it within the normalization phase. Subsequent, the collected knowledge was rehashed in order to provide it to the user in an appropriate way. Thereby the focus was put on enabling the user to perform the construction without any specific pre-knowledge and that he/she can reconstruct the creation process. For this reason, construction-packages are introduced, which are able to process an arbitrarily number of construction steps within the modeling phase in an automated manner. The scope of a package is determined by the knowledge engineer in regard of how sensible single steps of the procedure may be summarized. The user obtains access to the knowledge contained in a package by a graphical user interface allowing him to control the process intuitively. Therefore the system recognizes the current state of the working model and offers accordingly the next necessary step (Fig. $2+3$ ). After the execution of a construction package the user has the possibility to reconstruct all the transacted operations in the structure tree. This way he/she obtains a comprehension of the construction process as well as of the single methods, which are used within the process. Additionally, care was taken to use only simple basic functions for creating the parametric framework to allow major modifications of the model by simply editing sketch-elements via drag-and-drop. After each adjustment the user immediately sees the impact on the overall model. This also very intuitive approach helps to understand which consequences are caused by parametric changes and how the elements are linked to each other. On the one hand, this setup is meant to allow that inexperienced em-

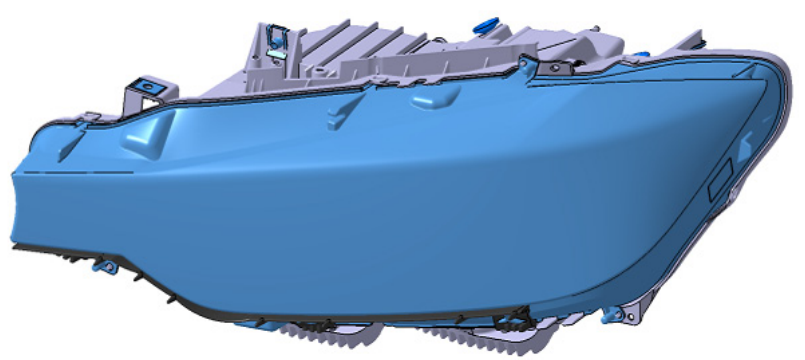

Figure 1. Automotive head lamp.

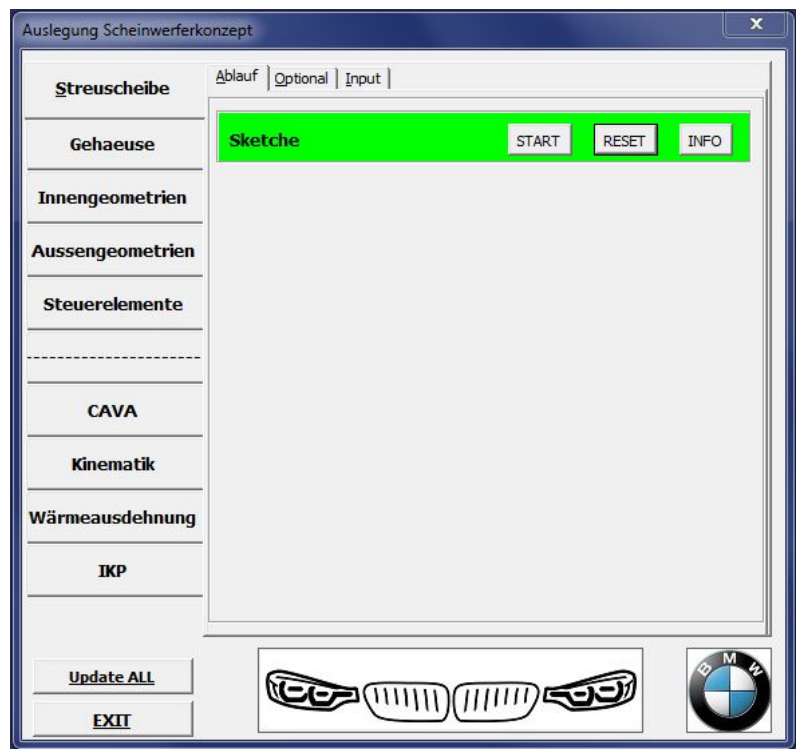

Figure 2. GUI at the beginning of the construction process [8].

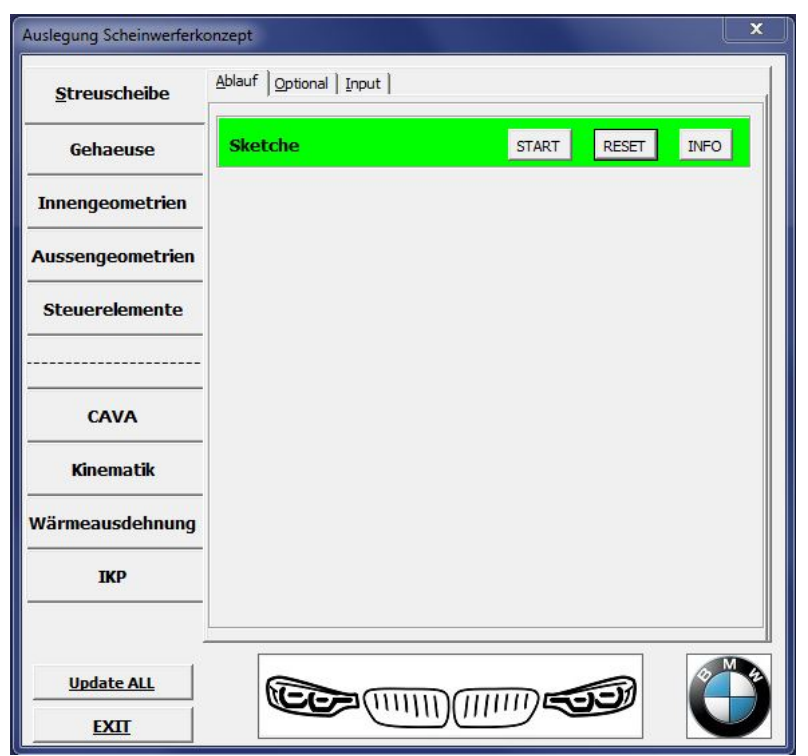

Figure 3. GUI at the end of the construction process [8].

ployees may be incorporated as fast as possible, resp. are enabled to work on the same level as experts. On the other hand the objective is that the user gets a better understanding of the construction process and the individual working steps with continuous usage. The intention is therefore that a learning effect occurs, allowing the user to create a CA-model with the KBE-application within the shortest possible time, according to the imagination of the user, with a high data-quality. 


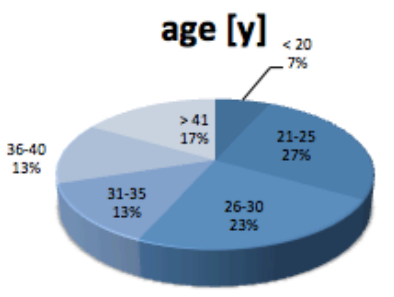

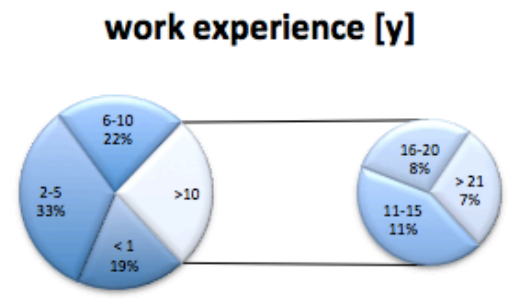

time working with CAD [y]

Figure 4. Experience of the participants.

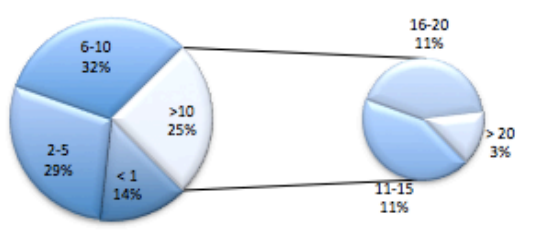

\section{EXPERIMENTAL STUDY}

\section{A. Description Of The Experiment}

To check the accomplishment of the addressed goals, an experimental study is performed with two construction tasks for the volunteers. Furthermore, a questionnaire must be answered before and after each construction. The field of participants is split randomly into three groups. The groups get equal tasks but the manner in which they are introduced differs. To experimental group one (V1) the principle procedure is illustrated by a video showing all working steps within about 10 minutes. During the experimental execution no questions concerning the KBEsystem were answered. V2 is introduced by a livedemonstration including a detailed explanation (duration about 15 minutes). Furthermore, there is the possibility to ask questions during the test procedure. The third group (V3) represents the control group, which has to solve the task without the KBE-application or any explanations.

The task is to create a pre-defined volume-body as fast and precise as possible. The model is supposed to be as flexible as possible, as well. The maximum time is set to 60 minutes. The input element is only a design-surface, similar to the real conditions of the development process. The desired body corresponds to the principle structure of a headlamp lens, but is a lot smaller to limit the necessary time for the test.

Rated are the criteria time for accomplishment, accuracy and flexibility. The time needed is assessed with a scale, as it is not possible to forecast the necessary time to complete the task of volunteers who achieve only a minor construction progress. Not solved but already far progressed constructions are rated by the time needed for an expert to complete the exercise. In order to evaluate the accuracy, experts compare the volunteers' models with the predefined volume body. The scale ranges from very accurate (1) to not comparable (5). For the measurement of the flexibility, there are three pre-defined variants, to which the models have to be able to be adopted. The volunteers do not know those variants in advance. The modifications consist of a simple and a major shape change as well as a structural rearrangement.

Aiming to verify a learning effect, the three groups are confronted with another construction task four to six weeks after the first test. In the second test, the intended body is a part of a real lens. The example has the same structure but a more complicated shape. That means that the solution principle must to be transferred to a more complex problem. None of the groups is allowed to ask questions. The assessment is the same as in the first test series.

\section{B. Participants}

The field of participants consisted of 30 employees (4 women, 26 men) of an automotive manufacturer and assisting service providers. Their age was between 23 and 55 years $(\mathrm{M}=31,9 ; \mathrm{SD}=9,9)$. The condition for the participation was having at least basic knowledge in handling a CAD-system. The working experience was in the middle 7,6 years $(\mathrm{SD}=9,1)$ and varied widely, which may be seen in Fig. 4. The level of experience throughout the tested persons also had a wide range. $86,7 \%$ never worked with headlamps before. $76,9 \%$ of the participants never used a component-specific construction system before.

\section{Results}

According to the questionnaire only $3,4 \%$ of the participants use the parametric possibilities of the CA-system to its full extent. $24,1 \%$ stated that they use those functionalities quite a lot whereas $43 \%$ use them hardly or not at all. Furthermore, 23,3\% maintained that they were incorporated sufficiently, able to start working afterwards. The average time for the incorporation towards the specific design tasks of the respective department was 10,3 hours $(\mathrm{SD}=12,7)$, which corresponds less then two working days. $60 \%$ of the polled did not get any instructions concerning the construction methods at all. The maximum was 160 hours (Fig. 5).

The evaluation of the construction tasks is represented graphically by means of Box-Whisker-Plots (Fig. $7-9$ ). The boxes comply with the mid-position $50 \%$, divided by the median. The whiskers show the extreme values. The mean value is added as blue rhombus. The results of the two experiments of one group are represented next to each other. This way the progression over the time period between the tests may be seen immediately. At first however, the results of the different groups for the first test are compared. First thing to recognize is that the control group reaches constantly the poorest performance. It can therefore be concluded, that the usage of the KBE-system leads to constantly better outputs regarding the addressed goals.

CAD incorporation time $[\mathrm{h}]$

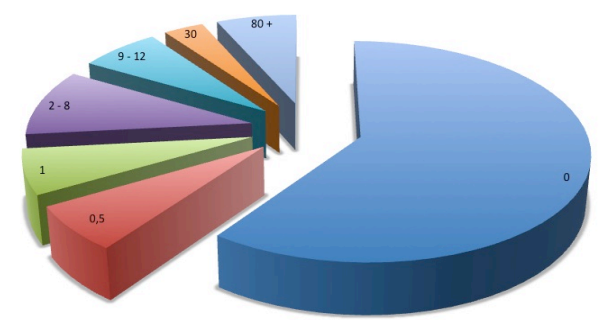

Figure 5. Incorporation time for specific design tasks. 
Especially V2, which has been introduced extensively, reaches good values with little scattering. The average was able to complete the execution within the given time. $25 \%$ could even finish before the time has elapsed. Noticeable with test group V1 is that the results for the flexibility are spread over the whole scale. Only exceptions could finish within the given period, but the models were far progressed and more accurate then the ones of group V3. None of this group was able to create a highly adoptable CA-model. From half of the participants the model could not be evaluated at all as the progression was to low.

Sighting the results of the second test, it is noticeable, that the two groups using the KBE-application could improve their performance, whereas the control group performed worse than before. Furthermore, it is apparent that test group V1 could improve a lot more then V2. For the criteria time and flexibility even better absolute values could be obtained. Except one participant, everybody was able to finish the task in the given time or faster. Additionally they were all able to create highly flexible models. The results of group V2 had a similar characteristic to the first experiment. However, V3 got worse in all factors. No one of the participants was able to finish the construction work in time.

Only $9,5 \%$ of the groups V1 and V2 stated that they think they are not capable to create a lens with the KBEapplication. $81 \%$ of the participants found such a system would be helpful for their regular work.

\section{CONCLUSIONS}

The introduction of the experimental groups V1 and V2 took 10 resp. 15 minutes, whereas it was only concerning the KBE-application. The fact that they achieved significantly better values then the control group not only shows, that the efficiency could be increased clearly. Furthermore, a data-quality was reached due to the KBE-system, which may normally only be expected after a timeconsuming incorporation process. Studies show, that there are usually big differences in the quality of constructions and the needed time dependent on the experience level of the design engineer [44]. Regarding how narrow the boxes are around the mean-value, it is noticeable that there is only a little scattering (especially in the second test) although the experience level of the participants varied a lot. Therefore it can be concluded, that inexperienced design engineers have been working on a similar level as their colleagues who have many years of experience in design works.

In the second test the volunteers had to fulfill a more complicated design task. According to this circumstance, the expectation was that test group V3 would not be able to achieve a better result. Indeed, the evaluation shows clearly that the test persons performed worse in all three categories. However, the participants who were supported by the KBE-application were able to improve their results, although the model got more complex. This fact shows, that there must have been a learning process in between resp. during the experimental procedures. For both of the groups, the average time needed sank under the maximum allowed time of 60 minutes. As the system is creating the elements in an automated manner, the workload is almost completely determined by the adoption of the models. As the needed time is reduced, even for more complex constructions demanding a transfer function, we can see that the contestants have gained a better understanding of the construction methodology. It has become clearer to them how the changes of single elements have an effect on the parametric structure and which elements have to be modified in order to obtain the desired result. Thereby not only the working time decreases as the evaluations on accuracy and flexibility show. The models can be adapted more accurate to the formulated goal respectively the idea of the design engineer. There was (hardly) no need for the participants to create elements or links within the parametric structure on their own which could restrict the flexibility.
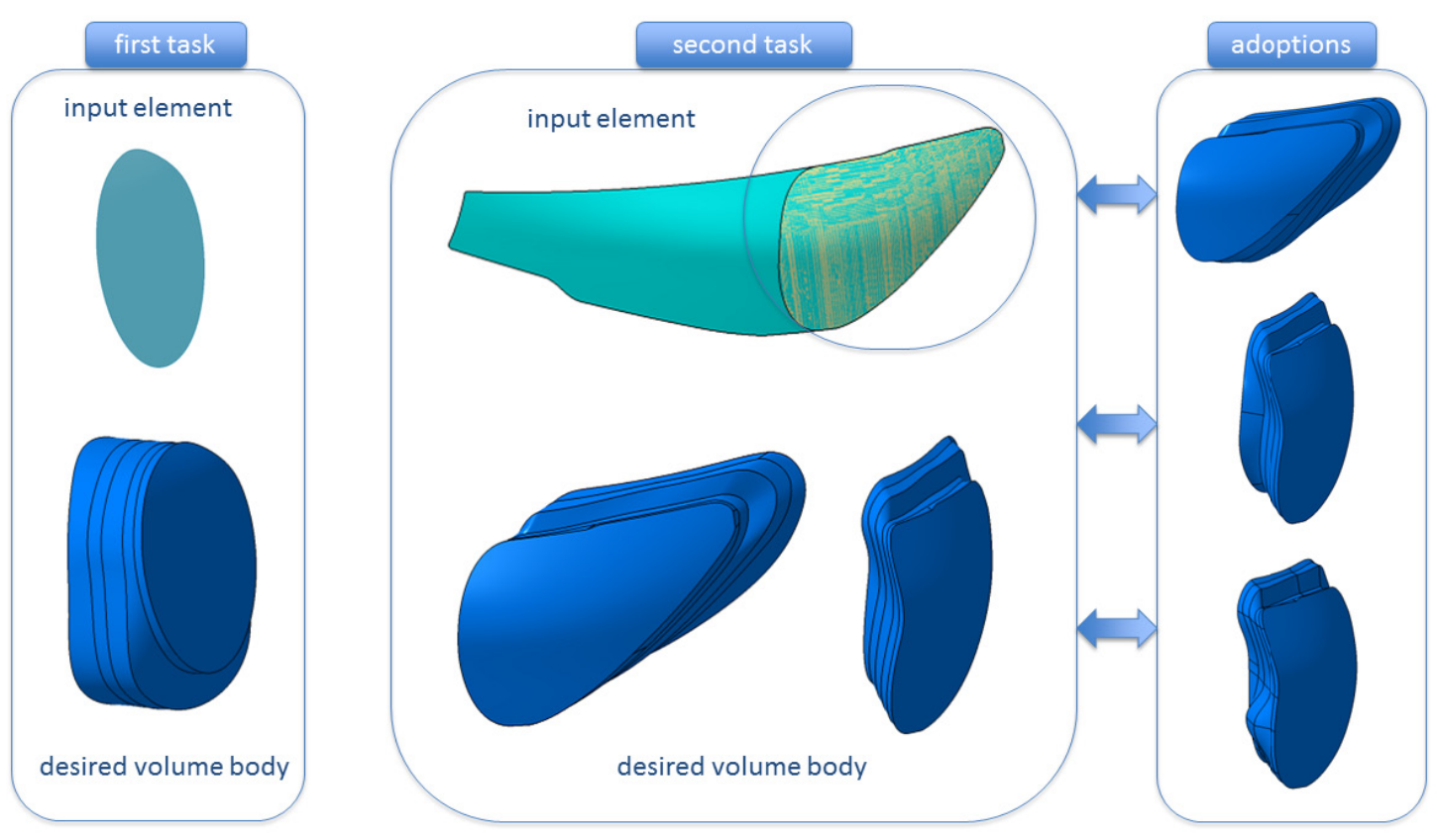

Figure 6. Construction tasks: Input elements, target bodies and model variations. 
Further noticeable are differences of the development progress between test groups V1 and V2. While V1 was able to enhance their performance on time and flexibility for over $30 \%$, group V2 achieved only about $7,5 \%$. The potential for V2 was not that big anymore as they had better values the first time, but for the two mentioned criteria, V1 could even achieve better overall values then the second test group. This may be explained by the increased learning effect, when reasoning gaps have to be closed by inferences. The part of those principle-based explanations was quite low for group V2, as rising questions could be posed to the experiment supervisor. The participants of test group V1, who did not have this option, had to solve upcoming problems on their own. It is for this reason clear, that it took them longer to perform the first construction task compared to V2. But it also led to a better understanding of the whole topic, which allowed a better performance even on a more complicated model, 4-6 weeks after the first try. Thus, the learning effect was bigger on test group V1.

\section{SUMMARY AND OUTLOOK}

A component-specific KBE-application was introduced containing expert knowledge of the construction process and the necessary working steps. This knowledge is provided to the user in form of construction-packages to guide him/her intuitively through the design process. This way, users of divers experience levels are able to perform equally efficient and high-quality construction works. The kind of the model setup as well as the provision of automatisms results in an unconscious learning process concerning the parametric construction methodology and the structure of the component. A 10-minute introduction is already enough to communicate all the information with which the remaining knowledge gaps can be filled autonomously. Current investigations deal with expanding this approach towards integrated hedges of the created models. Thereby no previous knowledge shall be demanded of the user as he/she is supported by the performance and interpretation of the tests.

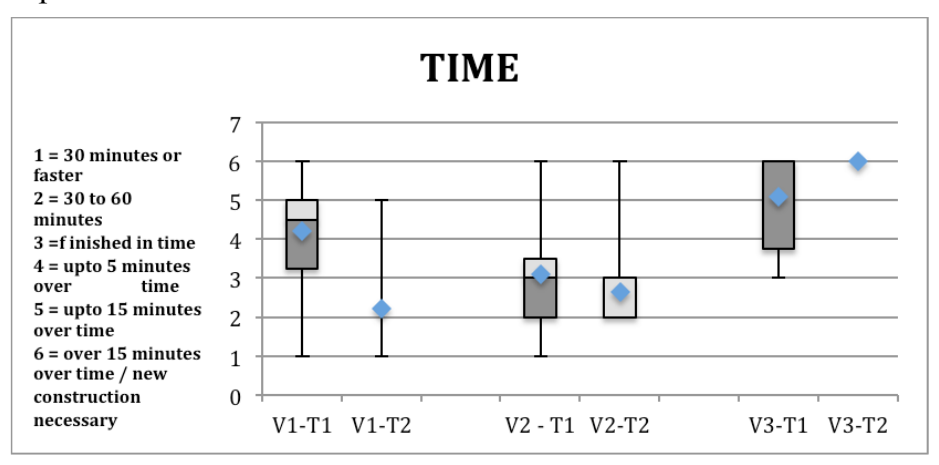

Figure 7. Evaluation of the time needed.

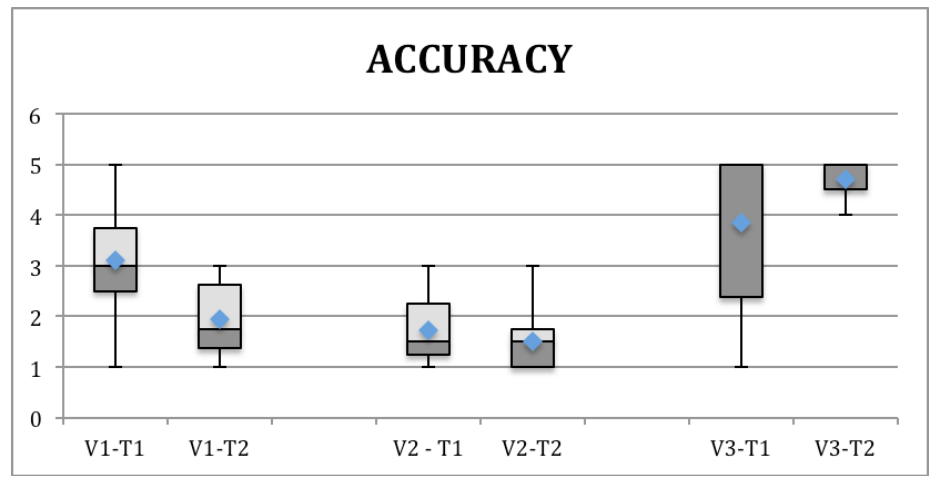

Figure 8. Evaluation of the accuracy.

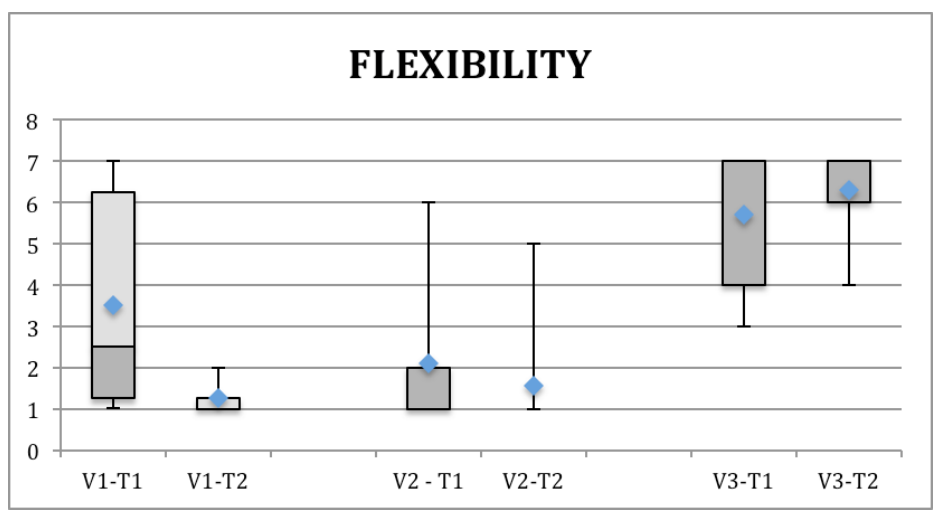

Figure 9. Evaluation of the flexibility. 


\section{REFERENCES}

[1] F. Hansen, "The turnover myth," Workforce Management, vol. 84, pp. 34-40, 2005.

[2] R. Andrea and P. Koehler, "Challenges associated with teaching $\mathrm{CAD} / \mathrm{CAE}, "$ in International CAD Conference and Exhibition, 2014, pp. 138-140. http://dx.doi.org/10.14733/cadconfp.2014.138140

[3] V. Salehi and C. McMahon, "Action research into the use of parametric associative CAD systems in an industrial context," in DS 58-5: Proceedings of ICED 09, the 17th International Conference on Engineering Design, Vol. 5, Design Methods and Tools (pt. 1), Palo Alto, CA, USA, 24.-27.08. 2009, 2009.

[4] P. Hehenberger, "An Approach to Model-based Parametric Design of Mechatronic Systems," presented at the International CAD Conference and Exhibition, Hong Kong, 2014. http://dx.doi.org/10.14733/cadconfp.2014.58-60

[5] P. Boart, P. Andersson, and B.-O. Elfström, "KNOWLEDGE ENABLED PRE-PROCESSING FOR STRUCTURAL ANALYSIS," presented at the 1st Nordic Conference on Product Lifecycle Management - NordPLM'06, Göteborg, 2006.

[6] G. La Rocca, Knowledge based engineering techniques to support aircraft design and optimization: TU Delft, Delft University of Technology, 2011.

[7] K. Amadori, M. Tarkian, J. Ölvander, and P. Krus, "Flexible and robust CAD models for design automation," Advanced Engineering Informatics, vol. 26, pp. 180-195, 2012. http://dx.doi.org/10.1016/j.aei.2012.01.004

[8] T. Hagenreiner, G. Engelmann, and P. Köhler, "Implicit Learning by Means of a Knowledge-Based Engineering System," 2015.

[9] A. S. Reber, Implicit learning and tacit knowledge: Oxford University Press, 1996. http://dx.doi.org/10.1093/acprof:oso/ 9780195106589.001.0001

[10] C. Lutz, Rechnergestütztes Konfigurieren und Auslegen individualisierter Produkte: Rahmenwerk für die Konzeption und Einführung wissensbasierter Assistenzsysteme in die Konstruktion: Dr. Hut, 2012.

[11] T. Hagenreiner and P. Köhler, "Component Optimisation via KBE Methods," ATZ worldwide, vol. 117, pp. 50-54, 2015.

[12] G. La Rocca and M. J. van Tooren, "Knowledge-based engineering to support aircraft multidisciplinary design and optimization," Proceedings of the Institution of Mechanical Engineers, Part G: Journal of Aerospace Engineering, vol. 224, pp. 1041-1055, 2010. http://dx.doi.org/10.1243/09544100J AERO592

[13] J. Schilling, Soziale Arbeit: Entwicklungslinien der Sozialpädagogik/Sozialarbeit: Luchterhand, 1997.

[14] A. Renkl. (2014). Learning from Worked Examples: How to Prepare Students for Meaningful Problem Solving. Available: http://teachpsych.org/ebooks/asle2014/index.php

[15] A. Renkl, "Wissenserwerb," in Pädagogische Psychologie, E. Wilk and J. Möller, Eds., ed: Springer, 2009, pp. 3-26. http://dx.doi.org/10.1007/978-3-540-88573-3 1

[16] A. Renkl, H. Gruber, S. Weber, T. Lerche, and K. Schweizer, "Cognitive load beim Lernen aus Lösungsbeispielen," Zeitschrift für Pädagogische Psychologie / German Journal of Educational Psychology, vol. 17, pp. 93-101, 2003.

[17] A. Renkl, "Learning from worked-out examples: A study on individual differences," Cognitive science, vol. 21, pp. 1-29, 1997. http://dx.doi.org/10.1207/s15516709 $\operatorname{cog} 2101 \_1$

[18] R. Stark, Lernen mit Lösungsbeispielen: Einfluss unvollständiger Lösungsbeispiele auf Beispielelaboration, Lernerfolg und Motivation: Hogrefe, Verlag für Psychologie, 1999.

[19] A. Renkl and R. K. Atkinson, "Structuring the transition from example study to problem solving in cognitive skill acquisition: A cognitive load perspective," Educational psychologist, vol. 38, pp. 15-22, 2003. http://dx.doi.org/10.1207/S15326985EP3801 3

[20] J.-A. LeFevre and P. Dixon, "Do written instructions need examples?," Cognition and Instruction, vol. 3, pp. 1-30, 1986. http://dx.doi.org/10.1207/s1532690xci0301 1

[21] K. VanLehn, "Cognitive skill acquisition," Annual review of psychology, vol. 47, pp. 513-539, 1996. http://dx.doi.org/10.1146/ annurev.psych.47.1.513
[22] B. Fonseca and M. Chi, "The self-explanation effect: A constructive learning activity," The handbook of research on learning and instruction, pp. 270-321, 2011.

[23] M. T. Chi, M. Bassok, M. W. Lewis, P. Reimann, and R. Glaser, "Self-explanations: How students study and use examples in learning to solve problems," Cognitive science, vol. 13, pp. 145182, 1989. http://dx.doi.org/10.1207/s15516709 $\operatorname{cog} 1302 \_1$

[24] J. Sweller and G. A. Cooper, "The use of worked examples as a substitute for problem solving in learning algebra," Cognition and Instruction, vol. $\quad 2, \quad$ pp. $\quad 59-89, \quad 1985$. http://dx.doi.org/10.1207/s1532690xci0201_3

[25] M. Ward and J. Sweller, "Structuring effective worked examples," Cognition and instruction, vol. 7, pp. 1-39, 1990. http://dx.doi.org/10.1207/s1532690xci0701 1

[26] J. Sweller, "Cognitive load during problem solving: Effects on learning," Cognitive science, vol. 12, pp. 257-285, 1988. http://dx.doi.org/10.1207/s15516709 $\operatorname{cog} 12024$

[27] J. Sweller, P. Ayres, and S. Kalyuga, Cognitive load theory vol. 1: Springer, 2011. http://dx.doi.org/10.1007/978-1-4419-8126-4

[28] S. Ohsuga, "Toward intelligent CAD systems," Computer-aided design, vol. 21, pp. 315-337, 1989. http://dx.doi.org/10.1016/ 0010-4485(89)90039-0

[29] U. Klemme and P. Köhler, "A Hybrid Redesign Strategy to Derive Load-Adaptive Parts," Computer-Aided Design and Applications, vol. 9, pp. 665-677, 2012. http://dx.doi.org/10.3722/cadaps. 2012.665-677

[30] VDI-2209, "3D product modelling," Verein Deutscher Ingenieure: 3 D Produktmodellierung, Düsseldorf, VDI-Verlag, p. 44, 2009.

[31] VDI-2218, "Information technology in product development. Feature Technology," ed: Beuth Verlag, Berlin, 2003.

[32] P. Köhler, Moderne Konstruktionsmethoden im Maschinenbau: Vogel Buchverlag, 2002.

[33] W. F. Bronsvoort, R. Bidarra, and P. J. Nyirenda, "Developments in feature modelling," Computer-Aided Design and Applications, vol. 3, pp. 655-664, 2006. http://dx.doi.org/10.1080/16864 360.2006.10738419

[34] S. Danjou and P. Koehler, "Challenges for design management," Computer-Aided Design and Applications, vol. 4, pp. 109-116, 2007. http://dx.doi.org/10.1080/16864360.2007.10738531

[35] C. B. Chapman and M. Pinfold, "The application of a knowledge based engineering approach to the rapid design and analysis of an automotive structure," Advances in Engineering Software, vol. 32, pp. 903-912, 2001. http://dx.doi.org/10.1016/S0965-9978(01) 00041-2

[36] R. Brimble and F. Sellini, "The MOKA Modelling Language," in Knowledge Engineering and Knowledge Management Methods, Models, and Tools. vol. 1937, R. Dieng and O. Corby, Eds., ed: Springer Berlin Heidelberg, 2000, pp. 49-56. http://dx.doi.org/10.1007/3-540-39967-4 4

[37] J. Kulon, P. Broomhead, and D. Mynors, "Applying knowledgebased engineering to traditional manufacturing design," The International Journal of Advanced Manufacturing Technology, vol. 30, pp. 945-951, 2006. http://dx.doi.org/10.1007/s00170-0050067-0

[38] K. Oldham, S. Kneebone, M. Callot, A. Murton, and R. Brimble, "MOKA-A Methodology and tools Oriented to Knowledge-based engineering Applications," N. Mårtensson, R. Mackay and S. Björgvinsson, Changing the Ways We Work, IOS Press, Amsterdam, pp. 198-207, 1998.

[39] G. La Rocca, L. Krakers, and M. J. van Tooren, "Development of an ICAD generative model for blended wing body aircraft design," in AIAA 2002 conference, USA, Sept 2002 AIAA 2002 5447, 2002.

[40] R. Curran, W. J. Verhagen, M. J. Van Tooren, and T. H. van der Laan, "A multidisciplinary implementation methodology for knowledge based engineering: KNOMAD," Expert Systems with Applications, vol. 37, pp. 7336-7350, 2010. http://dx.doi.org/10.1016/j.eswa.2010.04.027

[41] T. Hagenreiner and P. Koehler, "Concept Development of Design Driven Parts Regarding Multidisciplinary Design Optimization," in International CAD Conference and Exhibition, 2014, pp. 41-42. http://dx.doi.org/10.14733/cadconfp.2014.41-42

[42] T. Hagenreiner and P. Köhler, "Concept Development of Design Driven Parts Regarding Multidisciplinary Design Optimization," 
Computer-Aided Design and Applications, vol. 12, pp. 208-217, 2015. http://dx.doi.org/10.1080/16864360.2014.962433

[43] T. Hagenreiner, P. Köhler, and T. Manoharan, "CAD im Kontext der Industrie 4.0," in Entwerfen Entwickeln Erleben 2014 Beiträge zur virtuellen Produktentwicklung und Konstruktionstechnik, Dresden, 2014, pp. 497-508.

[44] C. J. Atman, R. S. Adams, M. E. Cardella, J. Turns, S. Mosborg, and J. Saleem, "Engineering design processes: A comparison of students and expert practitioners," Journal of Engineering Education, vol. 96, pp. 359-379, 2007. http://dx.doi.org/10.1002/ j.2168-9830.2007.tb00945.x

\section{AUTHORS}

T. Hagenreiner is with BMW AG, Munich, Germany and University of Duisburg-Essen, Duisburg.

G. Engelmann is with University of Dresden, Dresden.

P. Köhler is with University of Duisburg-Essen, Duisburg.

Submitted 08 May 2015. Published as resubmitted by the authors 02 June 2015. 